\title{
Quadrupole Coupling Assignments in Inorganic Periodic Systems by ab initio Calculation of Electric Field Gradients*
}

\author{
Michael H. Palmer ${ }^{1}$ and John A. Blair-Fish ${ }^{2}$ \\ ${ }^{1}$ Department of Chemistry, University of Edinburgh, West Mains Road, Edinburgh EH9 3JJ, Scotland \\ ${ }^{2}$ Edinburgh University Computing Service, Mayfield Road, Edinburgh EH9 3JZ, Scotland \\ Z. Naturforsch. 49a, 137-145 (1994); received July 23, 1993

\begin{abstract}
$\mathrm{Ab}$ initio SCF calculations were performed in the unit cell environment, making use of the periodic behaviour to compute a wave-function for the bulk material. Electric field gradient (EFG) calculations were performed on the resulting wave-functions, and these are compared with experimental quadrupole coupling parameters. Examples of inorganic molecular and ionic crystals (nitrogen, chlorine and lithium nitride) and minerals or partially covalent lattice structures (alumina, petalite, $\alpha$-quartz, boron oxide, boron nitride and sulphur nitride) are described. The effects of the basis set in these calculations are considered, and the limitations imposed by the nature of the calculation are described.
\end{abstract}

\section{Introduction}

Our previous studies of a variety of organic and inorganic molecules, each containing one or more ${ }^{14} \mathrm{~N},{ }^{10,11} \mathrm{~B}$ or ${ }^{33} \mathrm{~S}$ as quadrupolar nuclei came into two classes: (a) studies of individual molecules at equilibrium [1 -3] and (b) small groups of molecules [4-6], where a test molecule was surrounded by its nearest shell of neighbours from the crystal lattice. In (a) comparison was made with gas-phase data (usually microwave spectral results); the results of method (b) were compared with NQR data from the solid state. Neither of the above methods are suitable for nonmolecular structures such as (c) minerals, unless some attempt to terminate the lattice, perhaps by $\mathrm{H}$-atoms, is performed. A further problem with classes (b) and (c) is that the basis sets for the problem under consideration can become very large; this can be overcome by using different bases for the same element in different environments in the system, such that the basis is high quality near the nucleus in question, where the electric field gradient is being evaluated, but less satisfactory at distant positions [7]. The present paper will present a number of results using "CRYSTAL-92", an ab initio Hartree-Fock SCF program for periodic systems [8], with particular reference to non-transition metal inorganic compounds.

* Presented at the XIIth International Symposium on Nuclear Quadrupole Resonance, Zürich, July 19-23, 1993.

Reprint requests to Dr. Michael H. Palmer, Chemistry Department, University of Edinburgh, West Mains Road, Edinburgh EH9 3JJ, United Kingdom.

\section{Methods}

\subsection{General Methods}

For comparisons of ab initio calculations with microwave and other gas phase studies were either a single molecule or a small cluster is involved, the $a b$ initio technique is to determine the equilibrium geometry of the species in question and to evaluate the electric field gradient (EFG) tensor elements $q_{z z}$ (in atomic units) over the ground state wave-function $\Psi_{0}$ :

$$
q_{z z}=\left\langle\Psi_{0}\left|\left(3 z^{2}-r^{2}\right) / r^{5}\right| \Psi_{0}\right\rangle .
$$

The latter are then converted to nuclear quadrupole coupling constants (NQCC, $\chi_{z z}$ in $\mathrm{MHz}$ ) via the appropriate isotopic(I) quadrupole moment ( $Q_{\mathrm{I}}$ in barn):

$$
\chi_{z z}=e^{2} Q_{\mathrm{I}} q_{z z} / h=234.96 Q_{\mathrm{I}} q_{z z} .
$$

The $q_{z z}$ vary with the methodology, such as SCF, CI or multi-configuration SCF, and the basis set used in the calculation. In a comparison of $q_{i i}$ by various methods at a fixed structure, the nuclear term is constant; thus variations arise from the electronic term. So there is no one set of $q_{i i}$, but instead a family of such values, depending upon the details of the computational methods. In general, to be within about $10 \%$ accuracy of experimental magnitudes from MW or NQR studies of $\chi_{i i}$, it is necessary to use a double zeta (DZ) or better, basis of atomic orbitals in the SCF method. In general, such a level of accuracy will suffice for the assignment of experimental $\chi_{i i}$ from NQR spectra to the internal molecular axes. However, in cases where there are two quadrupole tensor elements of similar absolute value, i.e. the asymmetry parameter 
$(\eta)$ is very high, there may be difficulty in being sure that the computed quadrupole coupling tensor elements lie in the same directions as the experimental ones. Axially symmetric systems, with two $\chi_{i i}$ values identical, present no problems. In our previous work we treated the value of $Q_{\mathrm{I}}$ as a scaling parameter, using a correlation of $\operatorname{EFG}\left(q_{i i}\right)$ against $\chi_{i i}$ to evaluate the appropriate $Q_{\mathrm{I}}[1-3]$. For large basis sets, we expect to obtain values for $Q_{\mathrm{I}}$ similar to experiment, and this was the case [2] for ${ }^{10,11} \mathrm{~B}$. In the inorganic species described below we have insufficient examples of the $q_{i i}$ versus $\chi_{i i}$ relationships to evaluate a scaling factor for $Q_{\mathrm{I}}$, and so we adopt an experimental or previous theoretical value for $Q_{\mathrm{N}}$, and use (2) directly.

\subsection{Computational Methods in CRYSTAL-92}

As is conventional molecular SCF methods, the calculations can be performed in either a Gaussian orbital (GTO) with the radial function term as in

$$
\Phi_{n}=\sum_{j=1}{ }^{M} C_{i j} \exp \left(-k_{i} \alpha_{i} \cdot r^{2}\right),
$$

or a pseudo-potential basis, but here the basis functions ( $n$ per atom) are Bloch functions of GTO type. The GTOs are normally contracted with up to $M$ terms, leading to $N$ basis functions in total for the cell. The best atom optimised exponents will have $k_{i}=1$, but in the present work some will be scaled with $k_{i}$ greater than unity. The effect of this scaling is to make the AO decline more quickly with distance from the atomic nucleus which carries the function. Thus $k_{i}>1.0$ is more appropriate for a positively charged atom.

As well as the basis, the main data input is the crystallographic space group, unit cell parameters and the unique atoms. The electron density is sampled at a set of $K$ points in reciprocal space; these are specified in the input data and must give a relatively fine grid, otherwise SCF convergence will not occur. This remark is most critical where the unit cell contains many nuclei, as in some organic systems. Compared with molecular calculations, much more care is necessary in the choice of tolerances used for both the coulomb and exchange electron repulsion integrals; in the present work two types of tolerances $10^{-\mathrm{ITOL}}$ are set; these control parameters relating to overlap integrals within coulomb and exchange terms in relation to the distance between the cells in question $(\mathrm{ITOL}=6$ ) and whether the integral is to be used (ITOL $=14)$. In general, convergence is accelerated by high ITOL and a large number of $K$ points, but this leads to storage problems for the electron repulsion integrals and large SCF cycle times, respectively. SCF convergence is followed by one-electron molecular properties evaluation on the resulting wave-function (1).

\subsection{Basis Sets}

The molecules were represented by one of a series of basis sets; where possible we used a $\mathrm{DZ}[9,10]$ or better GTO set; these are comparable with our previous work [4-6]. Since CRYSTAL-92 computes electron repulsion integrals over products of radial functions and products of spherical harmonics, there is considerable saving of CPU-time and 2-electron integral filespace by the use of shared sp-radial function (3), as in the Pople STO-nG and N-31G series [11-14], that is, the exponents $\alpha_{i}$ are the same for the pairs $2 \mathrm{~s}$ and $2 \mathrm{p}_{x, y, z}$, or $3 \mathrm{~s}$ and $3 \mathrm{p}_{x, y, z}$, but the contraction coefficients $C_{i j}$ are different for $2 \mathrm{~s}$ and $2 \mathrm{p}$ etc. The first calculations for each molecular system made use of such functions, with 4-31G ( $\mathrm{H}$ atom) [11], 6-21G and 6-31G [12,13] (C-F) and 66-21G for $\mathrm{Na}-\mathrm{Cl}[14]$, and 1s (3) $2 \operatorname{sp}(3) 3 \operatorname{sp}(3) 3 d(2) 3 d(1) 4 \operatorname{sp}(2) 1 s p$ (1) for $\mathrm{Sc}-\mathrm{Zn}$ [15].

The use of shared exponents for sp-GTOs is generally an approximation, and where possible other bases were used. The requirement that the EFG is good close to the atomic nuclei means that a wide range of high exponents is required. In the crystalline state, atoms in different molecules lie relatively close to one another; the use of diffuse GTOs, which occur in the larger basis sets, is often impracticable, since SCF divergence [8] is experienced. This is a fundamental problem with the use of Bloch functions, and there appears to be no solution but to avoid the use of such functions. Thus bases where very low exponent $\left(\alpha_{i}<0.10\right)$ terms are either absent or can be removed on density grounds in the free atom or ion populations are essential. Since the metallic atoms in minerals are highly cationic, the GTOs which lead to catastrophic SCF behaviour are little populated, and this does not lead to any real loss of flexibility. The Roos and Siegbahn [16] $7 \mathrm{~s} 3 \mathrm{p} / 10 \mathrm{~s} 6 \mathrm{p}$ sets, contracted to $\mathrm{DZ}$ give better flexibility than $66-21 \mathrm{G}$ stets for second row atoms, but the Huzinaga 14s 10p (Al-Ar) [17] and 14s 9p 5d (Sc-Zn) [18] sets, were used, where practicable. In contrast, the anionic species such as $\mathrm{F}^{1-}$ or $\mathrm{O}^{2-}$, might be expected to require quite diffuse expo- 
nents; in these cases, a series of computations was made to determine the effect upon both the total energy and the EFG. However, in practice it was found that largely uncontracted valence shell bases were more important than the lowest exponent, and thus we studied most molecular systems with more than one basis. A feature of the Pople bases is very uneven populations within the basis of a particular atom; negative populations are relatively common. Thus we concentrate upon bases where the final contribution of each GTO is in the $0.3-0.8 \mathrm{e}$ region, thus allowing a balance between the functions; only in the very highest exponent GTOs are the final atomic populations smaller than $0.1 \mathrm{e}$, but these are necessary to obtain good representation of the shell near the nucleus. In general, in these CRYSTAL-92 calculations some optimization of the (best atom optimized) GTOs in the literature is appropriate, especially in largely ionic systems.

\section{Results for Molecular Crystals}

\subsection{The Nitrogen Crystal}

The nitrogen molecule forms three phases under differing levels of temperature and pressure [19]. Below $35.61 \mathrm{~K}$ at low pressures, the $\alpha$-phase exists (cubic, $\mathrm{P} 2 / 13)[20,21]$. This is converted to the $\beta$-phase above $60 \mathrm{~K}$ (hexagonal, P6/3 mmc) [22]. High-pressure $(\gamma)$ forms also exist ( $\mathrm{P}_{2} / \mathrm{mnm}$ [19] and $\mathrm{Pm} 3 \mathrm{n}$ [23]). The $\alpha$-phase has been analysed both as Pa3 and P2/1 3, the latter being more probable. The NQR spectral value for the quadrupole coupling constant in $\alpha$-nitrogen at $4.2 \mathrm{~K}$ is $4.642 \mathrm{MHz}[24,25]$, showing a single site; there exist no NQR data for the other phases. We have carried out a series of calculations with small and large basis sets for the $\alpha$-, $\beta$ - and $\gamma$-forms (Table 1). Because of the few variables it is practicable to seek the optimum structure. The $\operatorname{NQCC}(\chi)$ at all the ${ }^{14} \mathrm{~N}$ sites studied here used $Q_{\mathrm{I}}$ [26] in (2), $20.2 \times 10^{-31} \mathrm{~m}^{2}$. The cubic form cell studies (Table 1 ) show very similar behaviour to SCF single molecule and cluster calculations; at a DZ (4s 2p) level, the SCF EFG is low, leading to a value only $85 \%$ of the experimental one. Polarisation functions (1d and $\mathrm{G}^{*}$ series) lead to about $10 \%$ increase in the EFG. Optimisation of the NN bond length (Roos and Siegbahn basis) [16] in the 3-forms does not lead to much change in the EFG, and the equilibrium bond length is near $1.075 \AA$ in each crystal, between the crystallographic values [22]
Table 1. The nitrogen crystal.

(a) Cell studies of $\alpha-, \beta$ - and $\gamma$-nitrogen: effect of basis set on $q_{z z}$ :

\begin{tabular}{|c|c|c|c|c|c|}
\hline Cell & $N$ Basis & Type & Energy/a.u. & $q_{z z} /$ a.u. & $\chi_{z z} / \mathrm{MHz}$ \\
\hline \multirow[t]{3}{*}{$\alpha-\mathrm{N}_{2}$} & $\begin{array}{l}72 \\
72 \\
80\end{array}$ & $\begin{array}{l}3 s \text { } 2 p \\
6-31 G \\
4 s 2 p \\
(D Z)\end{array}$ & $\begin{array}{l}-4 \\
-4\end{array}$ & $\begin{array}{l}-1.1 \\
-1.0\end{array}$ & $\begin{array}{l}-5.2378 \\
-4.8168 \\
-3.9557\end{array}$ \\
\hline & $\begin{array}{l}112 \\
120\end{array}$ & $\begin{array}{l}3 \mathrm{~s} 2 \mathrm{p} 1 \mathrm{~d}^{\mathrm{a}} \\
4 \mathrm{~s} 2 \mathrm{p} 1 \mathrm{~d}^{\mathrm{b}} \\
(\mathrm{DZP})\end{array}$ & $\begin{array}{l}-435.09293 \\
-435.84183\end{array}$ & $\begin{array}{l}-1.1591 \\
-1.0359\end{array}$ & $\begin{array}{l}-5.5012 \\
-4.9166\end{array}$ \\
\hline & 178 & $5 \mathrm{~s} 4 \mathrm{p} 1 \mathrm{~d}$ & -43 & -1.3219 & -5.3024 \\
\hline$\gamma-\mathrm{N}$ & $\begin{array}{l}56 \\
60\end{array}$ & $\begin{array}{l}3 \mathrm{~s} 2 \mathrm{p} 1 \mathrm{~d}^{\mathrm{c}} \\
4 \mathrm{~s} 2 \mathrm{p} 1 \mathrm{~d}^{\mathrm{d}} \\
\text { (DZP) }^{\mathrm{D} Z \mathrm{P})}\end{array}$ & $\begin{array}{l}-217 \\
-217\end{array}$ & $\begin{array}{l}-1.1571 \\
-1.0414\end{array}$ & $\begin{array}{l}-5.4918 \\
-4.9425\end{array}$ \\
\hline$\beta-\mathrm{N}$ & 60 & $\begin{array}{l}4 \mathrm{~s} 2 \mathrm{p} 1 \mathrm{~d}^{\mathrm{e}} \\
(\mathrm{DZP})\end{array}$ & -217.91740 & -1.0734 & -5.0945 \\
\hline
\end{tabular}

a Optimum bond length with the $3 \mathrm{~s} 2 \mathrm{p} 1 \mathrm{~d}$ basis set $1.068 \AA$. b Optimum bond length with the DZP basis set $1.074 \AA$.

c Optimum bond length with the $3 \mathrm{~s} 2 \mathrm{p} 1 \mathrm{~d}$ basis set $1.074 \AA$

d Optimum bond length with the DZP basis set $1.0748 \AA$.

e Optimum bond length with the DZP basis set $1.0776 \AA$.

(b) Single molecule and clusters of the $\alpha$-form:

\begin{tabular}{lllll}
\hline$N$ Basis & Type & Energy/a.u. & $q_{z z} /$ a.u. & $\chi_{z z} / \mathrm{MHz}$ \\
\hline 20 & 4s 2p (SCF) & -108.87817 & -0.8825 & -4.1884 \\
30 & 4s 2p 1d (SCF) & -108.95985 & -1.0504 & -4.9854 \\
40 & 5s 5p 1d (SCF) & -108.97787 & -1.3065 & -6.2010 \\
40 & 5s 5p 1d (CI) & -109.33707 & -1.2622 & -5.9906 \\
80 & 4s 2p (5-mol) & -544.38993 & -0.8723 & -4.0140 \\
\hline
\end{tabular}

before and after librational correction. The differences between the 3-forms are small for a particular basis set, but the theoretical stability is $\alpha>\gamma>\beta$, with quadrupole coupling magnitude $\beta>\gamma>\alpha$.

\subsection{The Chlorine Crystal}

The chlorine molecule, like bromine and iodine, crystallises with space group Cmca $(Z=2)$ [27, 28]. The packing is asymmetric, with two molecules lying almost perpendicular at the end of the bond, and two further neighbours on opposite sides of the molecule. The symmetry axes lie perpendicular to the molecular axis, with local $\mathrm{C}_{2 \mathrm{~h}}$ symmetry. The nature of the packing has been widely discussed [29-32]; each atom has five neighbours within $4.0 \AA$, two intralayer and three interlayer. The NQR quadrupole coupling for solid chlorine is $108.952 \mathrm{MHz}$ [33]; the asymmetry parameters for each of the above halogens are $0.205,0.200$ and 0.40 , respectively [34], much larger for chlorine than earlier estimates [35]. 


\begin{tabular}{lllrrl}
\hline$N$ Basis & Type & Energy/a.u. & $q_{z z} /$ a.u. & $\chi_{z z} / \mathrm{MHz}$ & $\eta$ \\
\hline 56 & 6s 2sp 2sp 1d & -1791.51032 & 2.0648 & 39.61 & 0.0108 \\
68 & 8s 6sp 3sp 1sp 1sp & -1837.75200 & 6.0641 & 116.34 & 0.0078 \\
72 & 6s 6sp 2sp 1sp 1d & -1837.77175 & 5.7107 & 109.56 & 0.0221 \\
72 & 6s 2s 1s 1s 4p 1p 1p 1d & -1834.75067 & 5.2651 & 101.01 & 0.0220 \\
92 & 6s 3s 1s 1s 1s 1s 6p 1p 1p 1p 1d & -1837.91554 & 5.8222 & 111.70 & 0.0415 \\
108 & 5s 1s 2s 1s 1s 1s 1s 5p 1p 1p 1p 1p1d & -1837.92788 & 5.9253 & 113.67 & 0.0156 \\
\hline
\end{tabular}

Table 2. The chlorine crystal: energies, $q_{z z}$ and $\eta$ parameters.

\begin{tabular}{|c|c|c|c|c|c|}
\hline$N$ Basis & Type & Energy/a.u. & Centre & $q_{z z} /$ a.u. & $\chi_{z z} / \mathrm{MHz}$ \\
\hline & {$[38]$} & & ${ }^{14} \mathrm{~N}$ & +0.1395 & 0.6621 \\
\hline & & & ${ }^{7} \mathrm{Li}(1)$ & -0.0933 & 0.8791 \\
\hline & & & ${ }^{7} \mathrm{Li}(2)$ & +0.0484 & -0.4560 \\
\hline \multirow[t]{2}{*}{25} & $\mathrm{~N}[4 \mathrm{~s} 4 \mathrm{~s} 3 \mathrm{~s} 2 \mathrm{~s} 4 \mathrm{p} 3 \mathrm{p}]$ & -72.45110 & ${ }^{14} \mathrm{~N}$ & +0.0742 & 0.3521 \\
\hline & $\operatorname{Li}[3$ s 3sp] & & ${ }_{7}^{7} \mathrm{Li}(1)$ & -0.1126 & $\begin{array}{r}1.0613 \\
-06358\end{array}$ \\
\hline \multirow[t]{3}{*}{28} & $\mathrm{~N}[7 \mathrm{~s} 3 \mathrm{sp} 1 \mathrm{sp} 1 \mathrm{sp}]$ & -76.89903 & ${ }^{14} \mathrm{~N}$ & +0.0200 & 0.0949 \\
\hline & $\mathrm{Li}[6 \mathrm{~s} 1 \mathrm{sp}]$ & & ${ }^{7} \mathrm{Li}(1)$ & -0.0974 & 0.9174 \\
\hline & & & ${ }^{7} \mathrm{Li}(2)$ & +0.0461 & -0.4341 \\
\hline \multirow[t]{2}{*}{42} & $\mathrm{~N}[7 \mathrm{~s} 3 \mathrm{sp} 1 \mathrm{sp} 1 \mathrm{sp} 1 \mathrm{~d}]$ & -76.90082 & ${ }^{14} \mathrm{~N}$ & +0.0276 & 0.1311 \\
\hline & $\operatorname{Li}[6 \mathrm{~s} 1 \mathrm{sp}]$ & & ${ }_{7}^{7} \mathrm{Li}(1)$ & -0.1003 & 0.9448 \\
\hline \multirow{3}{*}{52} & $\mathrm{~N}[6 \mathrm{~s} 2 \mathrm{~s} 1 \mathrm{~s} 1 \mathrm{~s} 1 \mathrm{~s} 3 \mathrm{p} 1 \mathrm{p} 1 \mathrm{p} 1 \mathrm{~d}]$ & -76.90549 & ${ }^{14} \mathrm{Li}(2)$ & $\begin{array}{l}+0.0469 \\
+0.0026\end{array}$ & $\begin{array}{r}-0.4428 \\
0.0122\end{array}$ \\
\hline & $\mathrm{Li}[5 \mathrm{~s} 1 \mathrm{~s} 1 \mathrm{~s} 1 \mathrm{~s} 1 \mathrm{~d} 1 \mathrm{p} 1 \mathrm{p}]$ & & ${ }^{7} \mathrm{Li}(1)$ & -0.1081 & 1.0181 \\
\hline & & & ${ }^{7} \mathrm{Li}(2)$ & +0.0522 & -0.4923 \\
\hline
\end{tabular}

\begin{tabular}{llrllll}
\hline Basis & Centre & Total & s-AOs & $\mathrm{p}(x, y)$-AOs & $\mathrm{p}(z)$-AOs & d-AOs \\
\hline 52 & $\mathrm{~N}$ & 10.096 & 3.961 & 4.074 & 2.058 & 0.000 \\
& $\mathrm{Li}(1)$ & 1.955 & 1.929 & 0.008 & 0.018 & \\
& $\mathrm{Li}(2)$ & 1.975 & 1.948 & 0.022 & 0.003 & \\
\hline
\end{tabular}

Table 3 a. Lithium nitride: energy and NQCC.

Table $3 \mathrm{~b}$. Lithium nitride: mulliken populations.
We have studied the chlorine crystal with various sets and using the variations in cell parameters (Table 2) found by crystallography [28]. None of the results are satisfactory with respect to the asymmetry parameter, and this is also true of semi-empirical cluster calculations [31, 32]. The general conclusion to be drawn is that the atomic orbitals are not sufficiently diffuse to generate enough density at neighbour molecules, that is the level of intermolecular interaction is insufficient. So far, attempts at the inclusion of diffuse functions has caused catastrophic behaviour in the CRYSTAL-92 SCF programme. With the exception of the Pople type bases with shared sp-exponents, the values for $\chi_{z z}$ are within $5 \%$ of the experimental NQR result $[33,34]$.

\section{Results for Ionic Crystals and Lattices}

\subsection{Lithium Nitride, $\mathrm{Li}_{3} \mathrm{~N}$}

The crystalline structure is hexagonal $\mathrm{P} 6 / \mathrm{mmm}$ [36] and shows each $\mathrm{N}$ atom/ion enclosed by a hexagon of
Li ions in local $\mathrm{D}_{6 \mathrm{~h}}$ symmetry, and these are stacked in parallel sheets, with intervening $\mathrm{Li}$ ions, leading to two Li sites per unit cell. The LiN bond lengths are $\mathrm{N}-\mathrm{Li}(1)$ and $\mathrm{N}-\mathrm{Li}(2) 1.939$ and $2.130 \AA$, respectively, where $\operatorname{Li}(2)$ is the a-member of the hexagonal group. The structure has been considered with both covalent and fully ionic models, the latter having the nominally spherically symmetric $\mathrm{N}^{3-}$ ion. If the structure were fully ionic, the quadrupole coupling would be very small or zero; in practice, single crystal studies [37] lead to $\chi_{z z}$ at ${ }^{7} \mathrm{Li}$ (sites 1 and 2 ) and ${ }^{14} \mathrm{~N}$ to be 582,285 and $505 \mathrm{kHz}$, respectively. The ${ }^{14} \mathrm{~N}$ value is clearly small, showing as largely ionic structure. The signs of the two Li sites are found to be opposite, with the larger $\mathrm{Li}(1)$ value thought to be positive [37]. HartreeFock cluster calculations [38], using various basis sets have been performed on units of the lattice. The results are shown for the corresponding enclosed sites in Table 3 ; in that study, the $q_{z z}$ was compared with experiment using the earlier value for $Q_{\mathrm{N}}$ of $16.6 \mathrm{mBarn}$ rather than the current value of $20.2 \mathrm{mBarn}$, which 
leads to poorer agreement with experiment. Also included is a direct comparison of the Das [38] basis set calculation for the cell ( $25 \mathrm{AOs)}$ as opposed to a small cluster. The present calculations with the TZVP largest basis set clearly lead to very low $\chi_{z z}$ at $\mathrm{N}$; all the calculations show the sign reversal at the two $\mathrm{Li}$ centres; the present study gives better results at $\mathrm{Li}$ for the ratio of values at the two sites. However, the overall values are too large at $\mathrm{Li}$ and too small at $\mathrm{N}$, showing too much charge transfer. The Mulliken populations (Table $3 \mathrm{~b}$ ) show that at $\mathrm{N}$ the $2 \mathrm{p}$ orbital population exceeds the $\mathrm{p}^{6}$ for the $\mathrm{N}^{3-}$ atom, with a total population slightly over $10 \mathrm{e}$; the Li sites show some fine differences in $\mathrm{AO}$ populations, and these probably reflect the difference shown in the sign of the NQCC at the two sites.

\subsection{Boron Nitride, BN Hexagonal Form}

This is the graphite-like form of the polymer, which has quadrupoplar nuclei at all centres, and space group P-6m2 [39]. This lattice proved difficult to study owing to the lowest GTO valence exponents for boron in many basis sets; the Roos and Siegbahn [16] 7s 3p sets, decontracted in the valence shell (Table 4) were successful, but a wider range of exponents was accessible by scaling of the best atom Dunning 9s $5 \mathrm{p} \mathrm{DZ}$ set [10]. Optimization of the DZ valence shell exponents by a scaling factor near 1.5 was necessary to avoid divergence in the SCF programme. The NQR SQUID technique gives an ${ }^{11} \mathrm{~B}$ frequency of $1.467 \mathrm{MHz}$ [40] and hence $\chi_{z z} 2.934 \mathrm{MHz}$, which is identical to the
NMR value [41]. The calculated values (Table 4) are very close to experiment. The ${ }^{14} \mathrm{~N}$ NQCC does not seem to have been observed, but is likely to be relatively small. The degree of electron donation from $\mathrm{N}$ to $B$ in the $\pi$ system is 0.436 (Table $4 \mathrm{~b}$ ). The net charge on the $\mathrm{B}$ and $\mathrm{N}$ atoms is near $0.572 \mathrm{e}$, largely as a result of $\sigma$ donation from $\mathrm{B}$ to $\mathrm{N}$, being offset by the smaller amount of back-donation. The band structure of hexagonal $\mathrm{BN}$ has been described [42] by ab initio plane wave calculations, but the NQCC and atomic populations were not discussed.

\subsection{Boron Oxide, $\mathrm{B}_{2} \mathrm{O}_{3}$}

Analysis of the ${ }^{11} \mathrm{~B}$ and ${ }^{10} \mathrm{~B}$ fine structure in the NQR of crystalline boron oxide yields a ${ }^{11} \mathrm{~B}$ NQCC of $2.7011 \mathrm{MHz}$, with asymmetry parameter $0.0669[43$, 44]. The system was studied at the $P 3_{1}$ space group [45], with a DZ basis set. We note that two B sites are present in the lattice [45]; the calculated NQCC (Table 5) is effectively identical at both sites, with ${ }^{10} \mathrm{~B}$ magnitude $+2.9958 \mathrm{MHz}$, but with differing asymmetry parameters, 0.0230 and 0.1932 . The planar $\mathrm{BO}_{3}$ units are similar to that of the $\mathrm{BN}$ hexagonal structure above. The ${ }^{11} \mathrm{~B}$ NQCC in the 6-membered ring compound trimethoxyboroxine is $2.14 \mathrm{MHz}$, with asymmetry zero [46], and clearly this is consistent with the boron oxide experimental value and indicates a positive sign for the boroxine NQCC. A previous paper [47] has discussed the variation of NQCC in model compounds related to the borate glasses, but the present work is solely concerned with the crystal lattice.

\begin{tabular}{lllllr}
\hline AOs & Type & Cell energy & Centre & $q_{z z} /$ a.u. & $\chi / \mathrm{MHz}$ \\
\hline 36 & 5s 1s 1s 2p1p & -158.18668 & ${ }^{11} \mathrm{~B}$ & +0.3239 & 3.0893 \\
& & & ${ }^{14} \mathrm{~N}$ & -0.2799 & -1.3284 \\
48 & $5 \mathrm{~s} 1 \mathrm{~s} 1 \mathrm{~s} 1 \mathrm{p} 1 \mathrm{p} 1 \mathrm{p}$ & -158.27900 & ${ }^{11} \mathrm{~B}$ & +0.2908 & 2.7732 \\
& & & ${ }^{14} \mathrm{~N}$ & -0.2301 & -1.0922 \\
40 & 6s 1s 1s 1s 4p1p & & & & \\
& 1.5 DZ & -158.51650 & ${ }^{11} \mathrm{~B}$ & +0.3574 & 3.4083 \\
& & & ${ }^{14} \mathrm{~N}$ & -0.1586 & -0.7527 \\
92 & 5s 1s 1s 1s1s1s & -158.57083 & ${ }^{11} \mathrm{~B}$ & +0.3779 & 3.6043 \\
& 3p1p1p1p1d & & ${ }^{14} \mathrm{~N}$ & -0.1741 & -0.8265 \\
\hline
\end{tabular}

Table 4 a. Hexagonal boron nitride: energies, $q_{z z}$ and derived $\chi_{z z}$.

\begin{tabular}{lllllll}
\hline Basis & Centre & Total & s-AOs & $\mathrm{p}(x, y)$-AOs & $\mathrm{p}(z)$-AOs & $\mathrm{d}-\mathrm{AOs}(\sigma+\pi)$ \\
\hline 448 & $\mathrm{~B}$ & 4.428 & 2.691 & 1.256 & 0.414 & 0.067 \\
& $\mathrm{~N}$ & 7.572 & 3.375 & 2.614 & 1.564 & 0.018 \\
\hline
\end{tabular}

Table 4 b. Hexagonal boron nitride: mulliken populations. 


\subsection{The Corundum, $\alpha-\mathrm{Al}_{2} \mathrm{O}_{3}$ Lattice}

The $\alpha$-alumina crystal (corundum) crystallises [48] as $\mathrm{R}-3 \mathrm{C}$ with unit cell $\mathrm{Al}_{4} \mathrm{O}_{6}$; the $\mathrm{Al}$ atom is enclosed within two equilateral triangles of $\mathrm{O}$ atoms, and hence is axially symmetric, whereas the oxygen atoms have nonzero asymmetry. A previous ab initio [49] calculation using the CRYSTAL-92 programme used a $6-21 \mathrm{G}$ $\mathrm{AO}$ basis with optimization of low exponents and $\mathrm{d}$-functions on $\mathrm{Al}$ or $\mathrm{O}$; that work, while concentrating on the density of states, gave some EFG results, and these are included in Table 6 . The charge density

Table 5 a. Boron oxide: energies, $q_{z z}$ and derived $\chi_{z z}$.

\begin{tabular}{llllll}
\hline AOs & Type & Cell energy & Centre & $q_{z z} /$ a.u. & $\chi_{z z} / \mathrm{MHz}$ \\
\hline $150 \quad$ 6s 1s 1s 1s 3p1p & -822.80795 & ${ }^{11} \mathrm{~B}(1)$ & +0.3142 & +2.9967 \\
& & ${ }^{11} \mathrm{~B}(2)$ & +0.3140 & +2.9949 \\
& & ${ }^{17} \mathrm{O}(1)$ & +1.1751 & +7.0629 \\
& & ${ }^{17} \mathrm{O}(2)$ & +1.1776 & +7.0780 \\
& & & ${ }^{17} \mathrm{O}(3)$ & +1.2259 & +7.3681 \\
\hline
\end{tabular}

Table $5 \mathrm{~b}$. Boron oxide: mulliken populations.

\begin{tabular}{lllll}
\hline Basis & Centre & Total & s-AOs & p-AOs \\
\hline \multirow{2}{*}{150} & $\mathrm{~B}(1)$ & 3.519 & 2.378 & 1.140 \\
& $\mathrm{~B}(2)$ & 3.523 & 2.386 & 1.135 \\
& $\mathrm{O}(1)$ & 8.981 & 3.885 & 5.096 \\
& $\mathrm{O}(2)$ & 8.976 & 3.886 & 5.091 \\
& $\mathrm{O}(3)$ & 9.002 & 3.871 & 5.132 \\
\hline
\end{tabular}

from the X-ray structure [50] has also been refined to yield the charge density and EFG. The experimental ${ }^{27} \mathrm{Al}(I=5 / 2) \mathrm{NQR}$ parameters have been obtained [40], while the sign of $e^{2} Q q$ is found to be positive from NMR studies [51]. The dynamic polarisation NMR method for the ${ }^{17} \mathrm{O}$ quadrupole coupling yields $\chi_{z z}=2.167 \mathrm{MHz}$ with $\eta=0.517$ [52] in ruby; the presence of $0.13 \% \mathrm{Cr}^{3+}$ does not appear to cast doubt on these data [51]. These values at both the $\mathrm{Al}$ and $\mathrm{O}$ centres are close to the present calculated ones in Table 6.

\subsection{Petalite, the $\mathrm{LiAlSi}_{4} \mathrm{O}_{10}$ Lattice}

The structure [53] contains layers of folded $\mathrm{Si}_{2} \mathrm{O}_{5}$ linked by $\mathrm{Li}$ and $\mathrm{Al}$ tetrahedra, with space group $\mathrm{P} 2 / \mathrm{a}$. The ${ }^{27} \mathrm{Al} \mathrm{NQR}$ of petalite [40] gives an NQCC of $4.56 \mathrm{MHz}$ with asymmetry parameter 0.47 . The size of the unit cell made it necessary to compromise on basis sets, and a $360 \mathrm{AO}$ basis consisting of Pople-type shared sp-bases was utilised (Table 7); specifically this was $\mathrm{Li}$ [6s 3s 1p], $\mathrm{Al}$ [6s 6sp 1sp 1sp], $\mathrm{Si}$ [6s 6sp 2sp 1sp1d] and $\mathrm{O}$ [6s 2sp 1sp]. The reason for the Si basis being larger than that of $\mathrm{Al}$ was that the anionic nature of the silicate requires extra flexibility. The SCF total energy was -4308.13192 a.u., with a virial ratio $(1+V / T)$ of 0.99978 , which is surprisingly good for such a basis. The $\mathrm{Li}$ and (two) Si centres show very low EFG $\left(10^{-3}\right.$ a.u.), while the (six) $\mathrm{O}$ centres have quite

\begin{tabular}{llllllll}
\hline$N$ Basis & Centre & $q_{z z}$ & $\chi_{z z} / \mathrm{MHz}$ & Centre & $q_{z z}$ & $\eta$ & $\chi_{z z} / \mathrm{MHz}$ \\
\hline 66 & $\mathrm{Al}$ & 0.0470 & 1.5493 & $\mathrm{O}$ & -0.8067 & 0.5272 & -4.8485 \\
106 & $\mathrm{Al}$ & 0.0887 & 2.9273 & $\mathrm{O}$ & -0.5379 & 0.5287 & -3.2329 \\
126 & $\mathrm{Al}$ & 0.0719 & 2.3702 & $\mathrm{O}$ & -0.5006 & 0.5295 & -3.0087 \\
136 & $\mathrm{Al}$ & $0.048[49]$ & 1.58 & $\mathrm{O}$ & -0.436 & 0.496 & -2.62 \\
186 & $\mathrm{Al}$ & 0.0886 & 2.9207 & $\mathrm{O}$ & -0.4405 & 0.5580 & -2.6475 \\
\hline
\end{tabular}

Table $6 \mathrm{a}$. The $\alpha$-alumina crystal: $\mathrm{EFG}$ at $\mathrm{Al}(\eta=0)$ and $\mathrm{O}$.

\begin{tabular}{|c|c|c|c|c|}
\hline \multirow[t]{2}{*}{$N$ Basis } & \multirow[t]{2}{*}{ AO types } & \multirow[t]{2}{*}{ Energy/u.a. } & \multicolumn{2}{|c|}{ Mulliken populations } \\
\hline & & & $\overline{\mathrm{O}}$ & $\mathrm{Al}$ \\
\hline 66 & $\begin{array}{l}\mathrm{Al}[3 \mathrm{~s} 3 \mathrm{sp} 3 \mathrm{sp}] \\
\mathrm{O}[3 \mathrm{~s} 3 \mathrm{sp}]\end{array}$ & -1400.39468 & 8.731 & 11.904 \\
\hline 106 & $\begin{array}{l}\mathrm{Al}[6 \mathrm{~s} \text { 6sp 3sp } 1 \mathrm{sp}] \\
\mathrm{O}[6 \mathrm{~s} 2 \mathrm{sp} 1 \mathrm{sp}]\end{array}$ & -1417.28311 & 9.202 & 11.197 \\
\hline 126 & $\begin{array}{l}\mathrm{Al}[4 \mathrm{~s} 4 \mathrm{~s} 3 \mathrm{~s} 2 \mathrm{~s} 4 \mathrm{p} 3 \mathrm{p} 2 \mathrm{p} 1 \mathrm{~d}] \\
\mathrm{O}[6 \mathrm{~s} 3 \mathrm{sp} 1 \mathrm{sp}]\end{array}$ & -1417.76662 & 9.193 & 11.210 \\
\hline 136 & $\begin{array}{l}\mathrm{O}[6 \mathrm{~s} 2 \mathrm{sp} 1 \mathrm{sp} 1 \mathrm{~d}] \\
\mathrm{Al}[6 \mathrm{~s} 6 \mathrm{sp} 2 \mathrm{sp} 1 \mathrm{sp} 1 \mathrm{~d}]\end{array}$ & $-1417.315[49]$ & 9.18 & 11.22 \\
\hline 186 & $\begin{array}{l}\mathrm{O}[4 \mathrm{~s} 2 \mathrm{~s} 1 \mathrm{~s} 1 \mathrm{~s} 1 \mathrm{~s} 3 \mathrm{p} 1 \mathrm{p} 1 \mathrm{p} 1 \mathrm{~d}] \\
\mathrm{Al}[4 \mathrm{~s} 4 \mathrm{~s} 3 \mathrm{~s} 4 \mathrm{p} 3 \mathrm{p} 2 \mathrm{p} 1 \mathrm{~d}]\end{array}$ & -1417.90622 & 8.973 & 11.540 \\
\hline
\end{tabular}

Table $6 \mathrm{~b}$. The $\alpha$-alumina crystal: cell energies and atomic populations. 
Table $7 \mathrm{a}$. The petalite crystal: EFG at $\mathrm{Al}, \mathrm{Si}, \mathrm{Li}$ and $\mathrm{O}$.

\begin{tabular}{lcllcl}
\hline Centre & $q_{z z}$ & $\eta$ & Centre & $q_{z z}$ & $\eta$ \\
\hline $\mathrm{Li}$ & -0.0055 & 0.3802 & $\mathrm{Al}$ & -0.1587 & 0.5314 \\
$\mathrm{Si}(1)$ & -0.1398 & 0.1880 & $\mathrm{Si}(2)$ & -0.1590 & 0.2481 \\
$\mathrm{O}(1)$ & +1.1782 & 0.0183 & $\mathrm{O}(2)$ & +1.1651 & 0.0594 \\
$\mathrm{O}(3)$ & +1.1221 & 0.1613 & $\mathrm{O}(4)$ & +0.9563 & 0.3392 \\
\hline
\end{tabular}

Table $7 \mathrm{~b}$.

\begin{tabular}{|c|c|c|c|}
\hline$N$ Basis & AO Types & Energy/a.u. & $\begin{array}{l}\text { Mulliken } \\
\text { populations }\end{array}$ \\
\hline \multirow[t]{4}{*}{360} & $\mathrm{Al}$ [6s 6sp 1sp 1sp] & \multirow[t]{4}{*}{-4308.13192} & $\begin{array}{l}\mathrm{Al}[11.133], \\
\mathrm{Li}[2.037], \\
\mathrm{Si}(1)[12.490]\end{array}$ \\
\hline & Si [6s 6sp 1sp 1sp 1d] & & $\begin{array}{l}\mathrm{Si}(2)[12.496] \\
\mathrm{O}(1)[8.808]\end{array}$ \\
\hline & $\mathrm{O}[6 \mathrm{sp} 2 \mathrm{sp} 1 \mathrm{sp}]$ & & $\begin{array}{l}\mathrm{O}(2)[8.801] \\
\mathrm{O}(3)[8.786] \\
\mathrm{O}(4)[9.029]\end{array}$ \\
\hline & $\operatorname{Li}[6 \mathrm{~s} 3 \mathrm{~s} 1 \mathrm{p}]$ & & $\begin{array}{l}\mathrm{O}(5)[8.780] \\
\mathrm{O}(6)[9.029]\end{array}$ \\
\hline
\end{tabular}

large EFG (1.1 a.u.); the ${ }^{27} \mathrm{Al}$ single site has an EFG of -0.15876 a.u., which yields an NQCC of -5.2336 $\mathrm{MHz}$ with asymmetry parameter 0.5314 . Considering the size of the basis set, this is very satisfactory agreement with experiment and strongly suggests that the sign is negative.

\section{6. $\alpha$-Quartz}

Although there are no stable isotopes of silicon with spin $>1 / 2$, the $1779 \mathrm{keV}$ excited state [54] may provide some data on Si NQCC in minerals, in the same way that ${ }^{19} \mathrm{~F}^{*}$ data have been obtained. Thus we studied $\alpha$-quartz [55], which crystallises with space group $\mathrm{P}_{3}{ }_{3} 21$. The EFG at $\mathrm{Si}$ (Table 8 ) is quite significant in magnitude, with non-zero asymmetry; the absence of an atomic quadrupole moment does not allow conversion of these to NQCC at the present time. The ${ }^{17} \mathrm{O}$ centres, however, also have high asymmetry and large $(-8 \mathrm{MHz})$ coupling constants. There seems to be considerable scope for experimental studies of ${ }^{17} \mathrm{O}$ in silicates etc.; the NQCC for several silicate model compounds [56] have been reported; these show values in the range $2.85-4.1 \mathrm{MHz}$ for $\mathrm{SiO}_{4}^{4-}$ ions.

\subsection{The Sulphur Nitride Polymer $(\mathrm{SN})_{x}$ and $\mathrm{S}_{2} \mathrm{~N}_{2}$}

The sulphur nitride polymer $(\mathrm{SN})_{x}$ is a metallic compound $[57,58]$ at low temperatures and is formed
Table $8 \mathrm{a}$. The $\alpha$-quartz crystal: EFG at $\mathrm{Si}$ and O.

\begin{tabular}{lcccccc}
\hline$N$ Basis & Centre & $q_{z z}$ & $\eta$ & Centre & $q_{z z}$ & $\eta$ \\
\hline 162 & $\mathrm{Si}$ & -0.8369 & 0.8538 & $\mathrm{O}$ & +1.5349 & 0.6098 \\
186 & $\mathrm{Si}$ & -0.3948 & 0.6364 & $\mathrm{O}$ & +1.3853 & 0.5206 \\
204 & $\mathrm{Si}$ & -0.4138 & 0.7377 & $\mathrm{O}$ & +1.3627 & 0.5496 \\
\hline
\end{tabular}

Table $8 \mathrm{~b}$. The $\alpha$-quartz crystal: cell energies and atomc populations.

\begin{tabular}{|c|c|c|c|}
\hline$N$ Basis & AO types & Energy/a.u. & Mulliken \\
\hline 162 & $\mathrm{Si}[4 \mathrm{~s} 4 \mathrm{~s} 3 \mathrm{~s} 2 \mathrm{~s} 4 \mathrm{p} 3 \mathrm{p} 2 \mathrm{p}]$ & -2180.63388 & $\begin{array}{l}\text { Si [12.954], } \\
\text { O [9.045] }\end{array}$ \\
\hline 186 & $\mathrm{Si}[4 \mathrm{~s} 4 \mathrm{~s} 3 \mathrm{~s} 1 \mathrm{~s} 1 \mathrm{~s} 4 \mathrm{p} 3 \mathrm{p} 1 \mathrm{p} 1 \mathrm{p}]$ & -2181.07656 & $\begin{array}{l}\text { Si [12.866], } \\
\text { O [9.134] }\end{array}$ \\
\hline 204 & $\begin{array}{l}\mathrm{Si}[4 \mathrm{~s} 4 \mathrm{~s} 2 \mathrm{~s} 1 \mathrm{~s} 1 \mathrm{~s}] \\
\mathrm{Si}[4 \mathrm{p} 2 \mathrm{p} 1 \mathrm{p} 1 \mathrm{p} 1 \mathrm{p}]\end{array}$ & -2181.11667 & $\begin{array}{l}\mathrm{Si}[12.855] \\
\mathrm{O}[9.145]\end{array}$ \\
\hline
\end{tabular}

$N$ Basis Centre $q_{z z} \quad \eta \quad \chi_{z z} / \mathrm{MHz} \quad \chi_{y y} / \mathrm{MHz} \quad \chi_{x x} / \mathrm{MHz}$

(a) Electric field gradients at $\mathrm{S}$ and $\mathrm{N}$ in the polymer

$\begin{array}{lllllll}128 & { }^{33} \mathrm{~S} & +1.9316 & 0.1752 & -30.7714 & +18.0805 & +12.6908 \\ & { }^{14} \mathrm{~N} & +0.6465 & 0.6699 & +3.0684 & -2.5620 & -0.5064\end{array}$

(b) Electric field gradients at $\mathrm{S}$ and $\mathrm{N}$ in the $\mathrm{S}_{2} \mathrm{~N}_{2}$ molecule

$128 \quad{ }^{33} \mathrm{~S}+2.23380 .2975-35.5856+23.0868+12.4988$

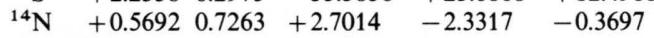

Table $9 \mathrm{~b}$. The $(\mathrm{SN})_{x}$ and $\mathrm{S}_{2} \mathrm{~N}_{2}$ mulliken analysis.

\begin{tabular}{lrlrlrll}
\hline$N$ Basis & \multicolumn{2}{l}{ Energy/a.u. Centre Total } & \multicolumn{2}{c}{ s-AOs } & p-AOs d-AOs \\
\hline$(\mathrm{SN})_{x}$ & & & & & & \\
128 & -1796.03965 & $\mathrm{~S}$ & 15.189 & 5.679 & 9.266 & 0.242 \\
& & $\mathrm{~N}$ & 7.811 & 3.760 & 4.015 & 0.036 \\
$\mathrm{~S}_{2} \mathrm{~N}_{2}$ & & & & & & \\
128 & -1796.08421 & $\mathrm{~S}$ & 15.266 & 5.750 & 9.300 & 0.216 \\
& & $\mathrm{~N}$ & 7.734 & 3.861 & 3.833 & 0.041 \\
\hline
\end{tabular}

from $\mathrm{S}_{2} \mathrm{~N}_{2}$. Both have space groups $\mathrm{P} 2{ }_{1} / \mathrm{c}$ but the $a$ and $b$-axes interchange during thermal polymerisation. The electronic structure of the cyclic SN dimer and short lengths of $(\mathrm{SN})_{x}$ have been studied $[59,60]$, while a small basis set lattice structure calculation, showing the development of band structure and the near absence of interchain interactions, has been reported [61]. The unit cell contains 8 atoms in each molecular case; we used a DZ basis with polarisation. The total energies (Table 9) for the cyclic dimer and the polymer were -1796.08421 and -1796.03965 a.u., 
respectively, showing that the monomer is more stable at low temperature. However, the presence of lowlying excited states [60] probably contributes to the thermal instability via an irreversible process.

The NQCC are quite different at either $\mathrm{N}$ or $\mathrm{S}$ in the two molecules; in the polymer, $\chi_{z z}$ for $\mathrm{S}$ lies along the external bisector of the NSN angle, while the other in-plane value is $\chi_{y y}$, with the lowest magnitude element lying out of the local plane $\left(\chi_{\pi}\right)$. At $\mathrm{N}$ the same order applies, with the local lone-pair value being $-2.56 \mathrm{MHz}$, much lower than that in many simple planar $\mathrm{N}$ atom situations (e.g. pyridine (-)4.584 MHz); the $\chi_{z z}$ is the local external bisector of the SNS angle. In the $\mathrm{S}_{2} \mathrm{~N}_{2}$ molecule, the $\chi_{z z}$ for $\mathrm{S}$ still lies on the NSN external bisector, but the local in-plane (radial with respect to the ring) and local $\pi$-tensor elements have switched in order relative to the polymer. At $\mathrm{N}$, the tensor elements are in the same order as in the polymer, with $\chi_{z z}$ again being the tangential component to the ring (external bisector of SNS).

\section{Conclusions}

This is the first of a series of papers on NQCC in which the CRYSTAL-92 programme is used. The differences from conventional SCF methods with bestatom bases make the latter a poor starting point for realistic calculations on largely cationic species, as in some of the minerals and related compounds studied here. The output NQCC can easily be a function of the basis set choice, and hence could lead to incorrect assignments unless care is taken. We have overcome this with studies using a wide range of bases, to confirm that the principal results are not markedly changed by the basis. In general, the use of shared sp-basis exponents leads to the highest computational efficiency, and because the exponents are not very diffuse, to the highest numerical stability. However, the lack of flexibility of these shared functions does not leads to satisfactory atomic (or ionic) populations, where negative populations seem common; we have found that the Huzinaga/Dunning bases of double and triple zeta valence shell (DZ and TZVP) quality can be utilised in these compounds by a combination of (a) removal of the lowest exponents and (b) scaling of the valence shell exponents to higher values; on the other hand, the anionic species can be studied by the best-atom bases reasonably satisfactorily. As currently constructed, CRYSTAL-92 can be very unstable in the SCF module; although is increases CPU-time significantly, and electron repulsion integral file length dramatically, the stability is much increased by using stringent values for the choice of rejecting or retaining integrals, and using as many $K$-points for electron density sampling as are possible for the system under consideration. Typical CPU-times for the larger $\mathrm{N}$ basis set calculations described in the Tables are 4-6 hours and disc space 8 Gbyte, using the computer mentioned in the Acknowledgements.

The results from the study on the $\mathrm{BN}$ and $\mathrm{B}_{2} \mathrm{O}_{3}$ polymer are sufficiently good for the signs of the NQCC to be certain, and similarly, the absolute signs at both $\mathrm{Li}$ centres in lithium nitride are confirmed. The ${ }^{27} \mathrm{Al}$ results in $\alpha$-alumina and petalite are also very satisfactory. The polymerisation of $\mathrm{S}_{2} \mathrm{~N}_{2}$ to the $(\mathrm{SN})_{x}$ polymer does not lead to major changes in the magnitude of the NQCC, but this is misleading, since two axes at the $\mathrm{S}$ centres switch in the process. The results for the molecular chlorine crystal are less satisfactory, although there is no difficulty with the NQCC; the asymmetry parameter found experimentally is consistent with that of both bromine and iodine, but we are unable to compute a value close to the experimental one. The inability to handle sufficiently diffuse exponents may be the problem. In the same way that ${ }^{19} \mathrm{~F}^{*}$ NQCC are now being studied, the question arises whether related excited states of other spin $1 / 2$ nuclei could be investigated. The ${ }^{29} \mathrm{Si}^{*}$ state would be a valuable probe for this nucleus, which occurs in so many minerals.

\section{Acknowledgements}

It is a pleasure to acknowledge Dr. V. R. Saunders (Daresbury Lab., UK) for the copy of the CRYSTAL-92 programme, and Digital Equipment Corporation (Livingston, UK) for the loan of a 4-processor (182 MHz) DEC 7640 running (VMS) AXP V1.5. 
[1] M. H. Palmer, Z. Naturforsch. 41 a, 147 (1986).

[2] M. H. Palmer, Z. Naturforsch. 45a, 357 (1990).

[3] M. H. Palmer, Z. Naturforsch. 47a, 203 (1992)

[4] M. H. Palmer, A. J. Blake, and R. O. Gould, Chem. Phys. 115, 219 (1987).

[5] M. H. Plamer, Chem. Phys. 115, 207 (1987)

[6] M. H. Palmer, A. J. Blake, M. M. P. Kurshid, and J. A. S. Smith, Chem. Phys. 168, 41 (1992).

[7] S. Gerber and H. Huber, Z. Naturforsch. 42a, 753 (1987).

[8] R. Dovesi, V. R. Saunders, and C. Roette, CRYSTAL 92; see also C. R. Pisani, R. Dovesi, and C. Roetti, HartreeFock ab-initio treatment of crystalline systems, Lecture Notes in Chemistry, Vol. 48, Springer Verlag, Heidelberg 1988. - V. R. Saunders, Faraday Symp. Chem. Soc. 19, 79 (1984).

[9] S. Huzinaga, J. Chem. Phys. 42, 1293 (1965).

[10] T. H. Dunning, J. Chem. Phys. 53, 2823 (1973).

[11] R. Ditchfield, W. J. Hehre, and J. A. Pople, J. Chem. Phys. 54, 724 (1971).

[12] J. S. Binkley, J. A. Pople, and W. J. Hehre, J. Amer. Chem. Soc. 102, 939 (1980).

[13] W. J. Hehre, R. Ditchfield, and J. A. Pople, J. Chem. Phys. 56, 2257 (1972).

[14] M. S. Gordon, J. S. Binkley, J. A. Pople, W. J. Pietro, and W. J. Hehre, J. Amer. Chem. Soc. 104, 2797 (1982).

[15] K. D. Dobbs and W. J. Hehre, J. Computational Chem 8, 861 (1987).

[16] B. Roos and P. Siegbahn, Theor. Chim. Acta 17, 209 (1970); ibid. 17, 199 (1970).

[17] S. Huzinaga, J. Chem. Phys. 53, 348 (1970).

[18] S. Huzinaga, J. Chem. Phys. 66, 4245 (1977).

[19] A. F. Schuch and R. L. Mills, J. Chem. Phys. 52, 6000 (1970).

[20] T. H. Jordan, H. W. Smith, W. E. Streib, and W. N. Lipscomb, J. Chem. Phys. 41, 756 (1964).

[21] S. J. La Placa and W. C. Hamilton, Acta Cryst. B 28, 984 (1972).

[22] D. Shiferl, D. T. Cromer, R. R. Ryan, A. C. Larson, R. Le Sar, and R. L. Mills, Acta Cryst. C 39, 1151 (1983).

[23] D. T. Cromer, R. L. Mills, D. Schiferl, and L. A. Schwalbe, Acta Cryst. B 37, 8 (1981).

[24] T. A. Scott, J. Chem. Phys. 36, 1459 (1962).

[25] K. Fujita, M. Suhara, and A. Sado, J. Magn. Reson. 17, 314 (1975).

[26] P. Pyykko and J. Li, Report HUKI 1-92 ISSN 07840365; an update of P. Pyykko, Z. Naturforsch. 47 a, 189 (1992).

[27] J. Donohue and S. H. Goodman, Acta Cryst. 18, 568 (1965).

[28] B. M. Powell, K. M. Heal, and B. H. Torrie, Molec. Phys. 53, 929 (1984).

[29] S. L. Price and A. J. Stone, Molec. Phys. 47, 1391 (1982).

[30] Z. Gamba, E. Halac, and H. Bonadeo, J. Chem. Phys. 80, 2756 (1984)

[31] J. Weber, V. A. Gubanov and A. A. V. Gibson, J. Magn. Reson. 20, 427 (1975).
[32] S. C. Nyburg, J. Chem. Phys. 48, 4890 (1968).

[33] R. Livingston, J. Chem. Phys. 19, 1434 (1951)

[34] S. Sengupta, G. Litzistorf, and E. A. C. Lucken, J. Magn. Reson. 41, 169 (1970).

[35] F. J. Adrian, J. Chem. Phys. 38, 1258 (1963).

[36] A. Rabenau and H. Schulz, J. Less-Common Metals 50, 155 (1976).

[37] K. Differt and R. Messer, J. Phys. C: Solid State Phys. 13, 717 (1980)

[38] P. C. Kelires, K. C. Mishra, and T. P. Das, Hyperfine Interactions 34, 289 (1987)

[39] R. S. Pease, Acta Cryst. 5, 356 (1952).

[40] C. Connor, J. Chang, and A. Pines, J. Chem. Phys. 93, 7639 (1990).

[41] A. H. Silver and P. J. Bray, J. Chem. Phys. 32, 288 (1960)

[42] K. T. Park, K. Terakura, and N. Hamada, J. Phys. C: Solid State Phys. 20, 1241 (1987).

[43] S. J. Gravina, P. J. Bray, and G. L. Petersen, J. NonCrystalline Solids 123, 165 (1990).

[44] A. H. Silver and P. J. Bray, J. Chem. Phys. 29, 984 (1958).

[45] G. E. Gurr, P. W. Montgomery, C. D. Knutson, and B. T. Gorres, Acta Cryst. 26, 906 (1970).

[46] M. A. Ring and W. S. Koski, J. Chem. Phys. 35, 381 (1961)

[47] J. A. Tossell and P. Lazzeretti, J. Non-Crystalline Solids 99, 267 (1988)

[48] A. Kirfel and K. Eichhorn, Acta Cryst. A 46, 271 (1990).

[49] L. Salasco, R. Dovesi, R. Orlando, M. Causa, and V. R. Saunders, Molec. Phys. 72, 267 (1991).

[50] J. Lewis, D. Schwarzenbach, and H. D. Flack, Acta Cryst. 38, 33 (1982).

[51] A. H. Silver, T. Kushida, and J. Lambe, Phys. Rev. 125, 1147 (1962).

[52] E. Brun, B. Derighetti, E. Hundt, and H. Niebuhr, Phys. Lett. 31 A, 416 (1970).

[53] T. Tagai, H. Ried, W. Joswig, and M. Korewaka, Z. Kristallogr. 160, 159 (1982).

[54] P. Raghaven, Atomic Data and Nuclear Data Tables 42. 189 (1989).

[55] Y. Le Page and G. Donnay, Acta Cryst. 32, 2456 (1976)

[56] J. A. Tossell and P. Lazzeretti, Chem. Phys. 112, 205 (1987).

[57] C. M. Mikulski, P. J. Russo, M. S. Saran, A. G. Mac Diarmid, A. F. Garito, and A. J. Heeger, J. Amer. Chem. Soc. 97, 6358 (1975).

[58] M. J. Cohen, A. F. Garito, A. J. Heeger, A. J. Mac Diarmid, C. M. Mikulski, M. S. Saran, and J. Kleppinger, J. Amer. Chem. Soc. 98, 3844 (1976).

[59] M. H. Palmer and R. H. Findlay, J. Molec. Struct. 92, 373 (1983).

[60] M. H. Palmer and M. F. Guest, Chem. Phys. Lett. 110, 187 (1986).

[61] M. Causa, R. Dovesi, C. Pisani, C. Roetti, and V. R. Saunders, J. Chem. Phys. 88, 3196 (1988). 